\title{
Is Life Based on Chirality of Pentavalent Elements Possible? Resolution of Stable Isomers, Enantiomers and Diastereomers of Pentavalent Nitrogen
}

\author{
Ilia Brondz \\ Norwegian Drug Control and Drug Discovery Institute (NDCDDI) AS, Ski, Norway \\ Email: ilia.brondz@gmail.com
}

How to cite this paper: Brondz, I. (2021). Is Life Based on Chirality of Pentavalent Elements Possible? Resolution of Stable Isomers, Enantiomers and Diastereomers of Pentavalent Nitrogen. Voice of the Publisher, 7, 44-55.

https://doi.org/10.4236/vp.2021.71004

Received: November 26, 2020

Accepted: March 13, 2021

Published: March 16, 2021

Copyright (๑) 2021 by author(s) and Scientific Research Publishing Inc. This work is licensed under the Creative Commons Attribution International License (CC BY 4.0).

http://creativecommons.org/licenses/by/4.0/

(c) (i) Open Access

\begin{abstract}
V-valent elements such as nitrogen, phosphorus, sulfur, and several others fulfill requirements for chirality. In the system on Earth, and with the present thermodynamic conditions-pressure, temperature, radiation, and others-the carbon atom's chirality is the primary factor in the creation of living creatures. However, even in our galaxy and surely elsewhere in the universe, there are places with very different temperatures, pressure, radiation and other conditions for life that differ from our model. Life on Earth in its present forms would not be imaginable if the average temperature was above $60^{\circ} \mathrm{C}$ because of instability in DNA, RNA, and protein molecules at such a temperature. Humankind is stuck in the doctrine that life must look like the model we are familiar with or be similar. However, other elements with the ability to create a stable chiral molecule can create an array of stable substances that can exist at higher temperatures and pressure, a different radiation level, and even in a sulfuric acid environment. The mentioned conditions do not exclude low solar radiation, low temperatures, high/low pressure or an acidic nitrogen/basic nitrogen environment. The universe is endless, but our imagination is limited by religious or materialistic indoctrination. The necessity to study $\mathrm{V}$-valent chiral elements that are part of complex stable molecules even in our system and to examine their stability or that of similar molecules at extreme conditions is clear. This paper presents several stable chiral substances with V-valent nitrogen. Intelligent life based on chirality besides that of chiral carbon is possible.
\end{abstract}

\section{Keywords}

Chirality, V-Valent Nitrogen, Phosphorus, Sulfur, Stable Chiral Substances 
with V-Valent Nitrogen

\section{Introduction}

Chemists usually refer to chirality-enantiomers, diastereomers and stereoisomers - in relation to the carbon atom, chiral carbon, or chiral center/centers. The general consensus is that carbon possesses the unique ability of a tetrahedral arrangement of valence electrons that gives it this ability. In the public there exists the perception that carbon is a building block of life because of the ability through enantiomery to create a multitude of complex and specialized isomers. Chirality was discovered in the early $19^{\text {th }}$ century by Jean-Baptiste Biot (1774-1862). Chirality can be seen everywhere in nature: in carbon consisting of molecules, creatures and even parts of creatures, and in mineral crystals as well as crystals of organic substances. Amino acids in living organisms are isomeric, containing chiral carbon. However, because the only requirement for chirality is that an atom is asymmetrical and has a tetrahedral shape, atoms such as nitrogen, phosphorus and sulfur do meet these requirements (Moss, 1996,

https://www.qmul.ac.uk/sbcs/iupac/stereo/, IUPAC, 2006). Chiral amines, which are difficult to separate due to their constant interconversion between the two enantiomeric forms, were the first to be discovered. Already in 1878, Jacobus Henricus van't Hoff proposed the space model of V-valent nitrogen in his book Ansichten Uber Die Organische Chemie, Volume 1. A long series of possible models was proposed after this. in 1890 by Willgerodt, J. Prokt. Chem., 41; in 1902 by Werner, Ber., 36; in 1905 by Jones, Trans. Chem. Soc., 87; and in 1908 by Bischoff, Ber., 23. Today, the space chiral model of $\mathrm{V}$-valent nitrogen is set forth by the International Union of Pure and Applied Chemistry (IUPAC). There now exist many substances with pentavalent nitrogen that are stable isomers; some of them are enantiomers and have been resolved (Phillipson et al., 1976; Brondz, 2013; Brondz and Brondz, 2012). Diastereomers are relatively easy to separate (resolve) because their physical properties, such as boiling point and solubility in liquids or gases, are different enough to allow for normal chromatographic separation. The real challenge lies in resolving enantiomers, because they have identical physical and chemical properties, except for their spatial arrangement, crystallization in levo- and dextro-crystals and rotation of planepolarized light in opposite directions. Resolution (chromatographic separation) of enantiomers, therefore, requires a different approach, for example, the use of a column with a chiral stationary phase or chiral selector. Another approach is to transform enantiomers into diastereomers, separate them, and then turn them back into enantiomers. In the course of the discussion in this paper, the importance of resolution of stereoisomers with $\mathrm{V}$-valent nitrogen is shown to lie in the necessity to determine if these substances exist in a pure stable form without interconverting one enantiomeric form into the other. It is not important what type of molecules they are; what is important is that they are stable. If stable 
$\mathrm{V}$-valent nitrogen molecules of relatively simple composition with small or medium molecular weight can exist in nature (Brondz and Brondz, 2012), this suggests that complex heavy molecules with $\mathrm{V}$-valent nitrogen can also exist. In this review, it was possible to present evidence of the existence and presence of stable enantiomers at one asymmetric nitrogen (Brondz and Brondz, 2012) as well as a diastereomeric presence at two different nitrogen in the same molecule (Brondz and Brondz, 2012). These molecules are stable at temperatures above $100^{\circ} \mathrm{C}$.

\subsection{Discovery of Chirality}

Chirality was discovered in the early 19th century by Jean-Baptiste Biot, who found certain compounds in solution can rotate a plane-polarized beam of light. Rotation can be either clockwise, known as dextrorotatory, or counterclockwise, known as levorotatory. Chirality is a case of isomerism. Biot investigated crystals of tartaric acid, a common acid found in wine. The origin of this phenomenon was later explained by the famous French chemist Louis Pasteur (1822-1895) in 1848 as being due to molecular differences between the solutions. Pasteur carried on Biot's research on tartaric acid crystals and was eventually able to produce a sample of pure levotartaric acid. Chirality is a property that can be seen everywhere in nature, not only at a molecular level. It is a term that refers to a pair of objects that are not superposable on one another. The word itself is de-

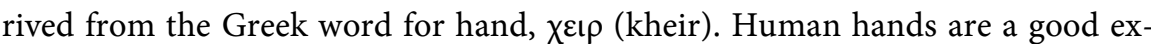
ample of chirality because one hand cannot be superposed upon the other, both facing in the same direction. Objects are chiral if they are mirror images of one another.

\subsection{Nature of Chirality}

The precise definition of chirality as given by the IUPAC states that chirality is "The geometric property of a rigid object (or spatial arrangement of points or atoms) of being non-superposable on its mirror image; such an object has no symmetry elements of the second kind (a mirror plane, $\sigma=S_{1}$, a center of inversion, $i=S_{2}$, a rotation-reflection axis, $S_{2 n}$ )" (Moss, 1996, https://www.qmul.ac.uk/sbcs/iupac/stereo/, IUPAC, 2006). In terms of the Valence Bond theory, chirality arises from the sp3 hybridization of a single-bonded carbon atom. This gives the carbon atom a tetrahedral shape, in which one bond must be out-of-plane. If all four substituents on a given carbon atom are different, then the atom is chiral, because no matter how the compound is rotated, its mirror image will not be superposable on it (Figure 1). Such a carbon atom is called an asymmetric carbon atom, as per the IUPAC definition (Moss, 1996, https://www.qmul.ac.uk/sbcs/iupac/stereo/, IUPAC, 2006). It can be shown that the number of possible stereoisomers of a molecule is $2 \mathrm{n}$, where $\mathrm{n}$ is the number of asymmetric carbon atoms. This is an exponential growth rate, suggesting that larger molecules of, for example, biological origin may easily have hundreds of stereoisomers. 


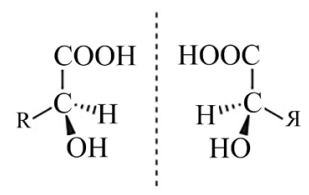

Figure 1. No matter how the compound is rotated, its mirror image is not superposable.

\subsection{The Nomenclature of Stereoisomers}

Stereoisomers are named using the Cahn-Ingold-Prelog priority rules. In this system, each chiral center in a molecule is considered by itself and its substituents are ranked, with the group having the atom with the highest atomic number first. After all, four substituents have been considered, the order of increasing priority dictates the configuration of the stereocenter. If the substituents' priority increases clockwise around a stereocenter, then it is prefixed with an R (Latin, rectus, for right). If the priority increases counterclockwise, the stereocenter is prefixed with an S (Latin, sinister, for left). The D- and L-system is mainly used in connection with biochemistry, more specifically when referring to amino acids. The system relies, for historical reasons, on glyceraldehyde as a chiral standard. Because many amino acids are similar to glyceraldehyde, it is a good starting point for comparison. When considering a given amino acid, its configuration is compared with that of the glyceraldehyde enantiomer. If the amino acid in question has a configuration like (R)-glyceraldehyde, it is D- (Figure 2); otherwise, it has an L-configuration.

There are other conventions as well. Of interest is the (+)- and (-)-system and the $\mathrm{D}$ - and L-system. The reason for using the $(+)$ - and (-)-system is that the $\mathrm{R} / \mathrm{S}$ system is not sufficient to determine in what direction a given molecule will rotate the plane of polarized light. An enantiomer can be named by the direction in which it rotates the plane of polarized light. In the (+)- and (-)-system, molecules that rotate plane-polarized light in the clockwise direction are prefixed $(+)$ and ones that rotate light in the opposite direction are prefixed (-). If it rotates the light clockwise, that enantiomer is labeled $(+)$; its mirror image is labeled $(-)$. The $(+)$ and $(-)$ isomers have also been termed $d$ - and $l$, respectively (for dextrorotatory and levorotatory). As early as 1923, Wohl and Freudenberg introduced the use of prefix $l$ - or $d$ - to the family of amino acids to denote the configuration of the $\alpha$-carbon atom in an amino acid. The direction of rotation of the plane of polarized light was notified in parentheses as (+) or (-) sign depending on the rotation direction.

\subsection{Chiral Atoms in Organic Molecules besides Carbon}

While carbon tends to be the prime focus in discussing chirality, especially in organic chemistry, other atoms exhibit chiral properties. Because the only real requirement for chirality is that an atom is asymmetric and has a tetrahedral shape, atoms such as nitrogen, phosphorus and sulfur meet the requirement. In the case of nitrogen and sulfur, one of the corners of the tetrahedron need not 
even be a bond; simply having a lone electron pair satisfies the requirement for chirality. The latter can be seen in chiral amines, which are difficult to separate due to their constant interconversion between the two enantiomeric forms. However, five valent nitrogen in $\mathrm{N}$-oxide molecules from natural sources (Phillipson et al., 1976, https://www.qmul.ac.uk/sbcs/iupac/stereo/, Brondz, 2013; Brondz and Brondz, 2012) presents enantiomerism toward chiral nitrogen. The substances can be resolved by chromatography, even on a nonchiral column, owing to the presence of chirality in asymmetric carbons in the same molecules and because of rigid ring structures (Figure 3). Semi- and synthetic stable $\mathrm{N}$-oxides also exist and can be separated (Figure 4).

Pholcodine is a semisynthetic derivative of morphine. Natural morphine has five asymmetric carbons (Figure 4).<smiles></smiles>

Figure 2. Glyceraldehyde of D-configuration.
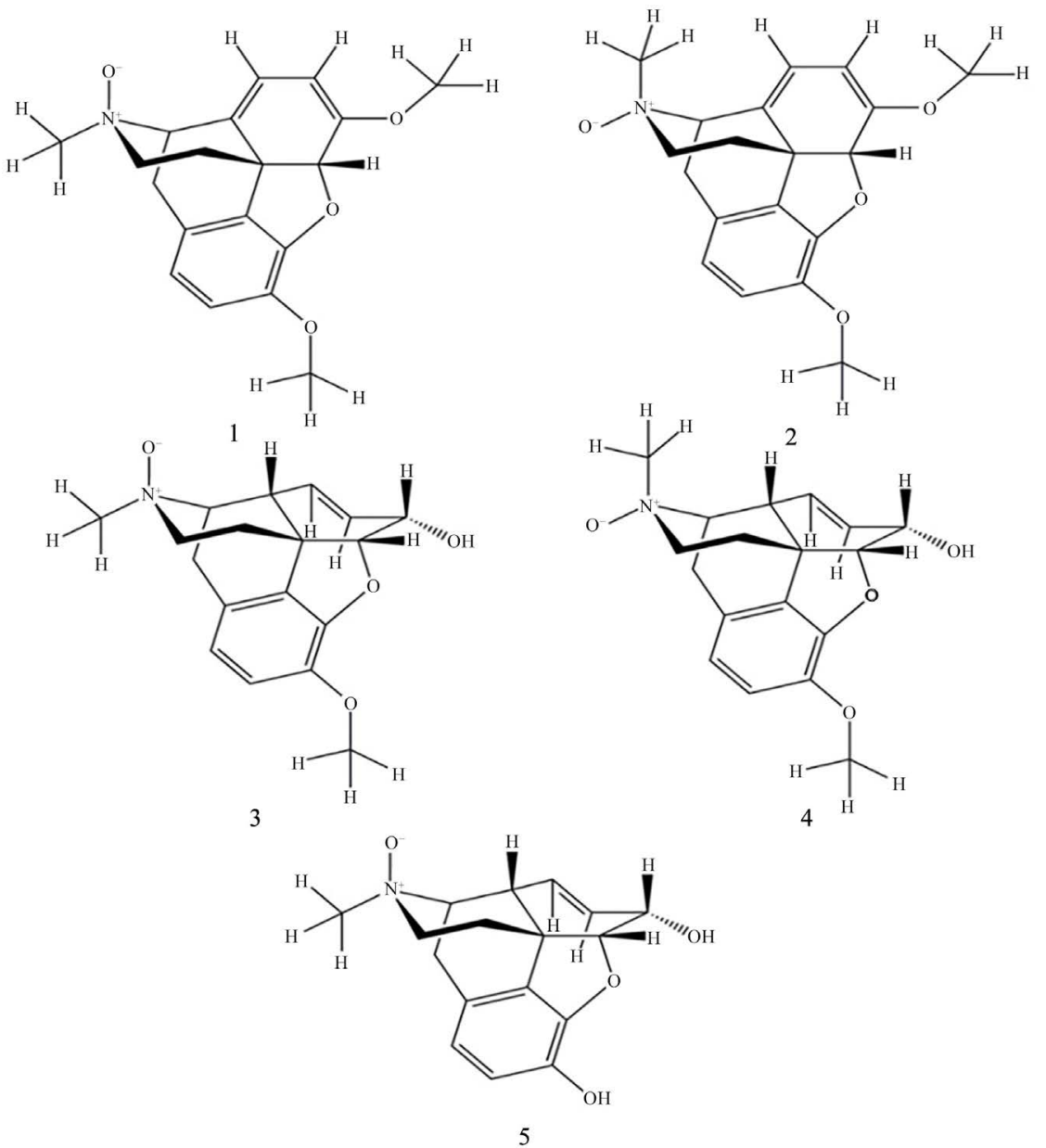

Figure 3. Opioid $N$-oxides with pentavalent nitrogen. 


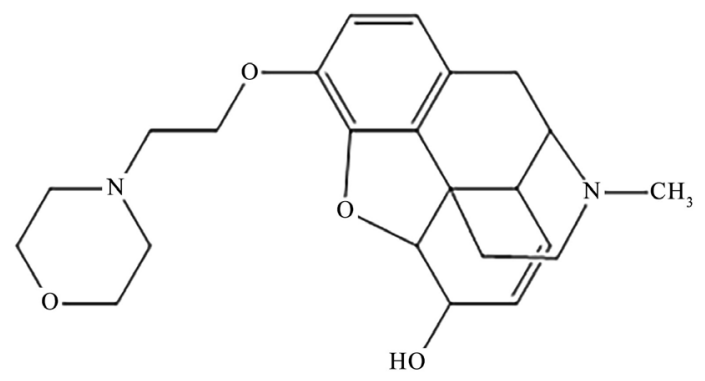

Figure 4. Pholcodine, a semisynthetic trivalent nitrogen substance.

By degradation of pholcodine, two substances (oxides) were accumulated in solution and chromatographically resolved (Figure 5).

The resolution of these two $\mathrm{N}$-oxides of pholcodine, UK2 and UK7, using an achiral column was possible owing to the presence of asymmetric carbons.

Both substances exhibit a mass spectrum (MS) $[\mathrm{M}+\mathrm{H}]^{+}$with $\mathrm{m} / \mathrm{z} 415$ and similar fragmentation (Figure 6).

It was also possible to separate into two individual substances the $N$, $N$-dioxide of pholcodine described by (Brondz and Brondz, 2012). The MS fragmentation spectra of these two substances with two chiral $N, N$-atoms are shown in Figure 7.

\section{What Is the Difference between Isomer, Enantiomer and Diastereomer?}

It is notable that an isomer, need not be an example of chirality at all. There are many forms of isomers: constitutional isomers, positional isomers, cis-trans isomers, gross formula isomers, enantiomers, diastereomers and several others. The latter, enantiomers and diastereomers, refer to differences in the spatial arrangement between two given molecules. A constitutional isomer is simply a molecule with the same gross molecular formula as another one; however, constitutional isomers differ in the order in which the atoms are connected. The other name for constitutional isomers is structural isomers. The physical, as well as chemical, properties of two constitutional isomers may be completely different. Constitutional isomers are not within the scope of this review; because they tend to have so little in common, separating them is rarely a problem. However, some long-standing confusion has been reported, and two constitutional isomers are presented in Figure 8.

Chromatographic separation of these substitutional isomers was achieved using GC-MS, HPLC and SFC on nonchiral columns (Brondz et al., 2003; Brondz et al., 2004b; Brondz et al., 2004a; Brondz et al., 2005c; Brondz \& Klein, 2005; Brondz et al., 2005a; Brondz et al., 2005b).

\section{The Challenge to Separate Homologues and Isomers}

The separation of homologues and isomers is typically not a major task for chromatography. The volatile molecules can be separated using GC without difficulty; however, polar molecules demand some attention and can be separated 
using SFC (Brondz et al., 2007); however, they do not pose a limitation for gas chromatography-mass spectrometry with supersonic molecular beams (Brondz et al., 2009). Several underivatized fatty acids, $n$-alcohols and $n$-alkanes were separated for the first-time using GC in 1983 (Brondz et al., 1983b; Brondz et al., 1983a; Brondz, Olsen, \& Greibrokk, 1983; Brondz and Olsen, 1984b). However, the normal approach is to use derivatization to achieve less polarity and more volatility in the substances (Brondz and Olsen, 1984a). Positional isomers of fatty acids such as $2-\mathrm{OH}_{-}{ }_{\mathrm{Cl4}: 0}$ and $3-\mathrm{OH}{ }^{-}{ }_{\mathrm{C} 14: 0}$ were separated after derivatization (Brondz and Olsen, 1984b). More complex and more polar molecules after derivatization can be separated (Brondz and Olsen, 1984a; Brondz and Olsen, 1985) including isomers such as D-glycero-D-manno-heptose and L-glycero-D-mannoheptose (Brondz and Olsen, 1985). The separation of large isomeric molecules without derivatization can be achieved using GC if they are thermostable at the volatilization temperature (Brondz et al., 2004b; Brondz et al., 2005a) or by using HPLC (Brondz et al., 2005b) SFC (Brondz et al., 2005c), (Brondz et al., 2007) or special techniques such as gas chromatography-mass spectrometry with supersonic molecular beams (Brondz et al., 2009).

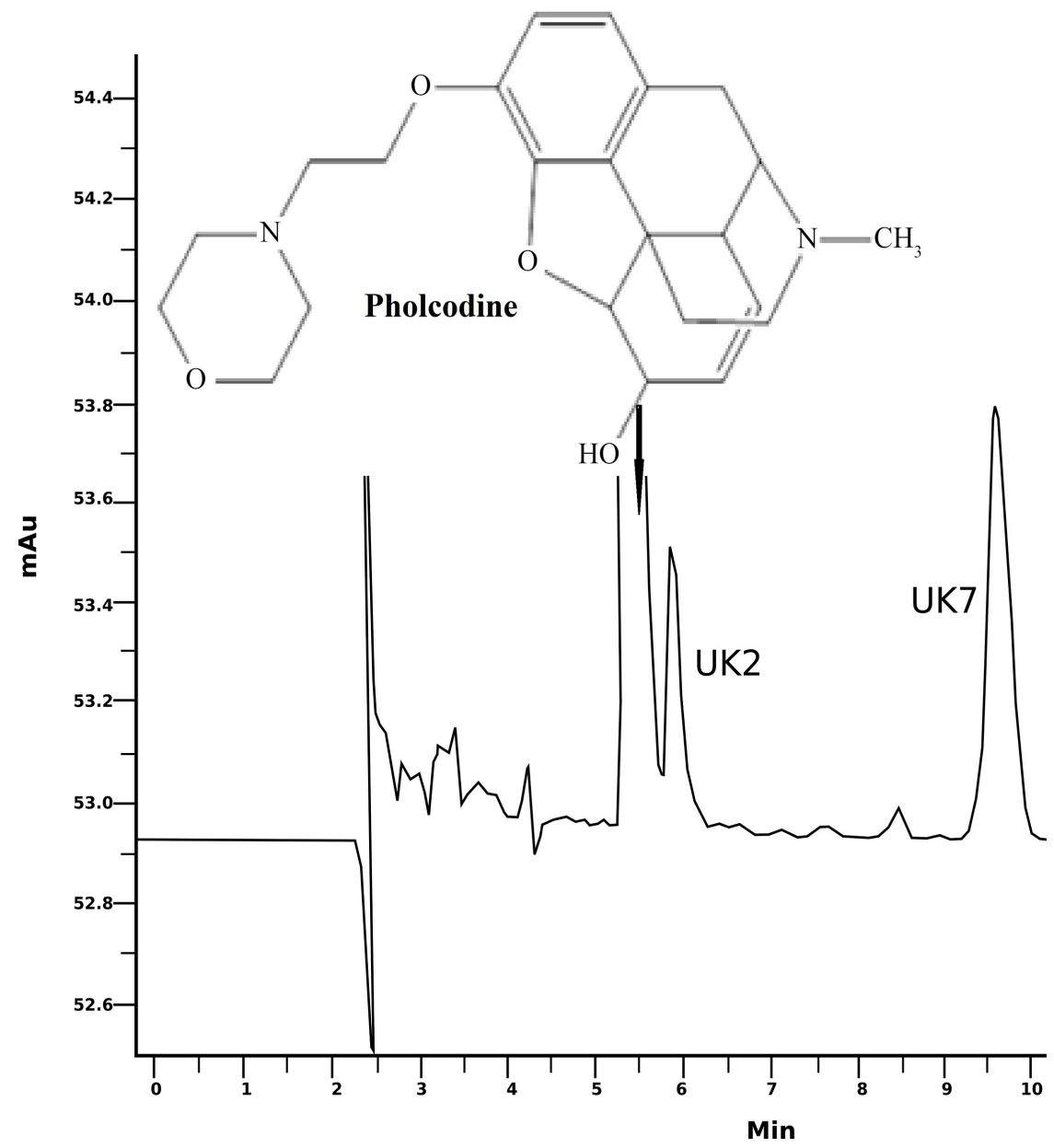

Figure 5. Two peaks, UK 2 and UK 7, are shown on the HPLC chromatogram. The substances are $N$-oxides of pholcodine as described by (Brondz and Brondz, 2012). 

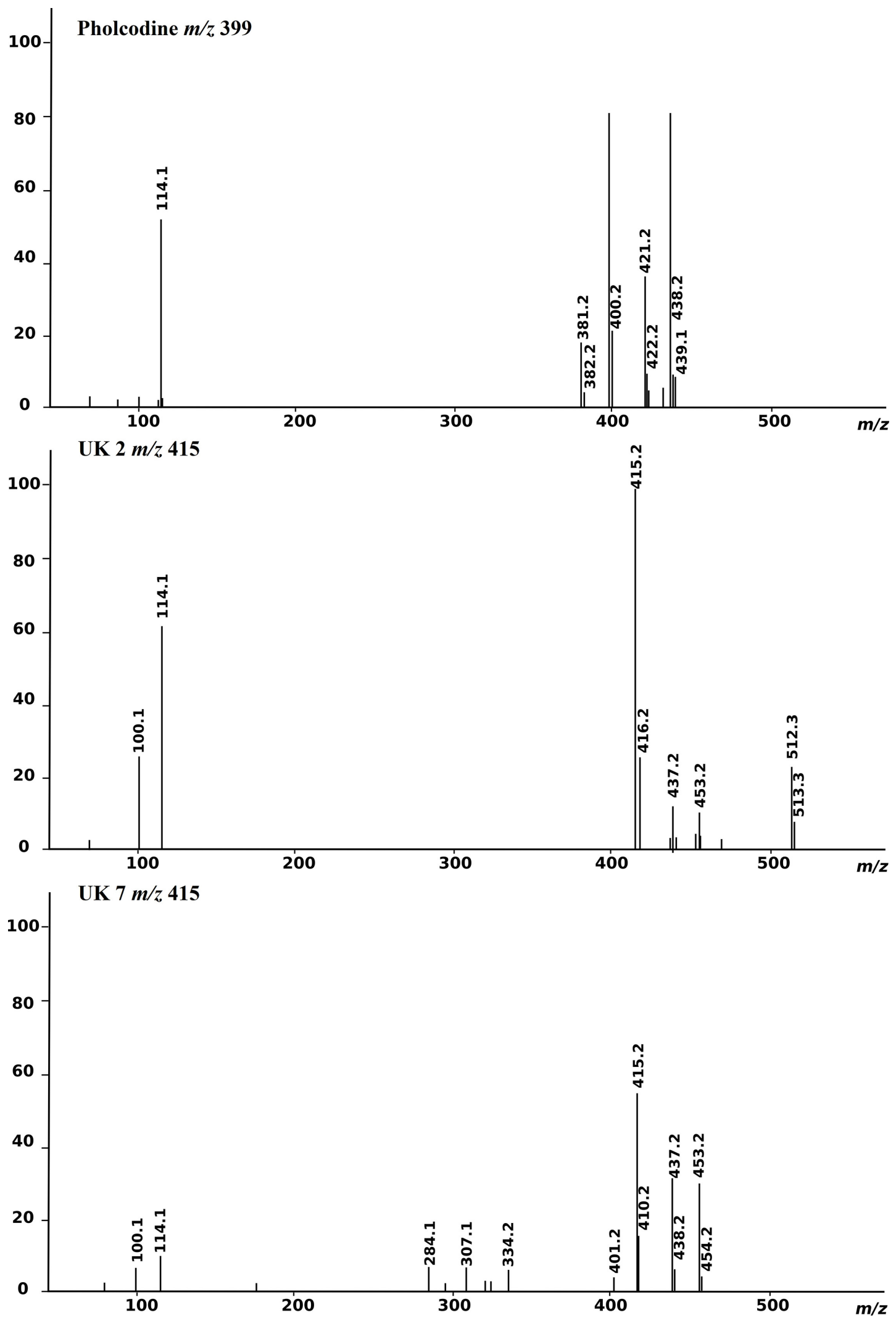

Figure 6. The MS fragmentation of the resolved in Figure 5 of these two $N$-oxides of pholcodine, UK 2 and UK 7, using an achiral column was possible owing to the presence of asymmetric carbons: in this case, the substances can be considered as diastereomers (Brondz and Brondz, 2012). 

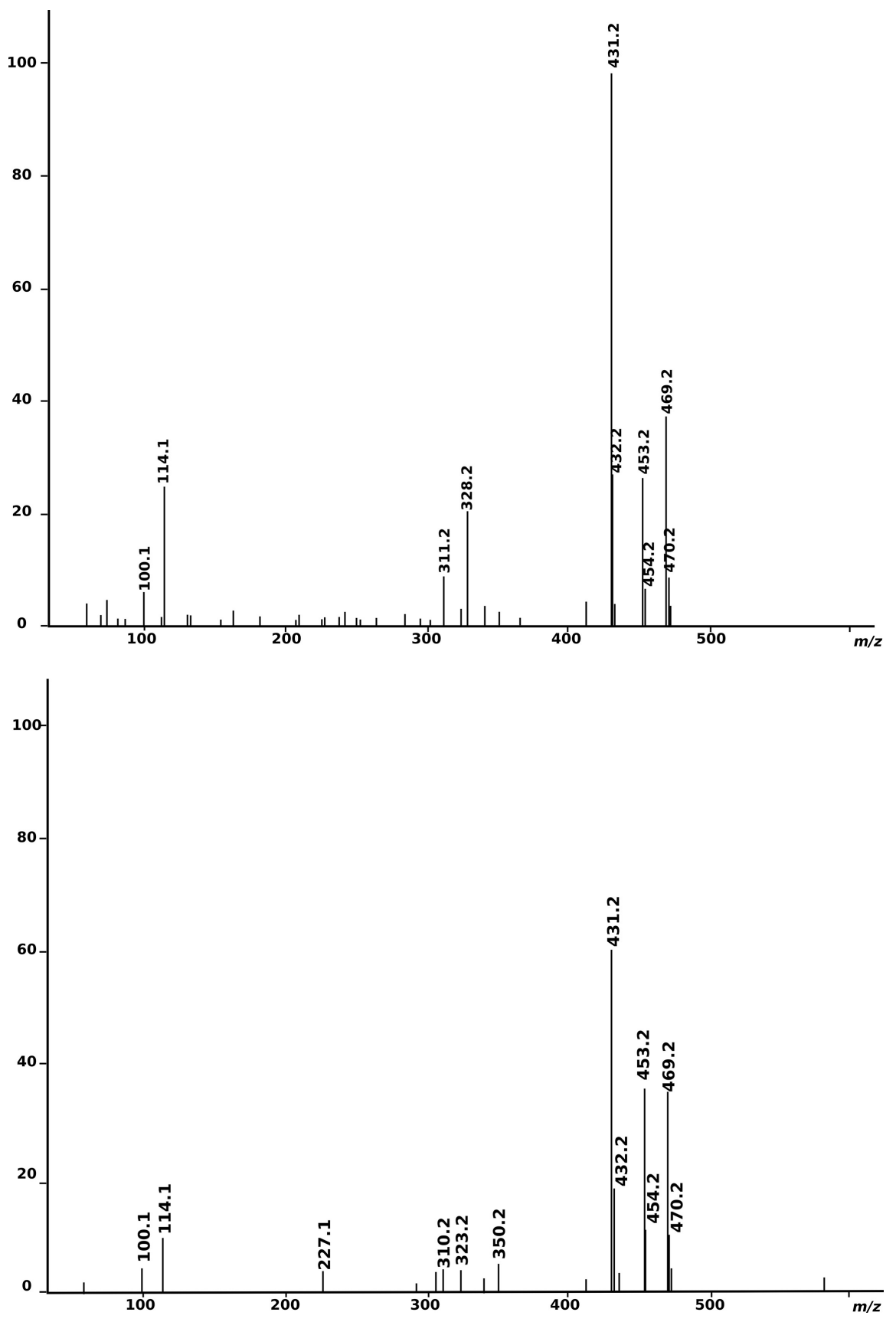

Figure 7. The MS fragmentation of the resolved the $\mathrm{N}, \mathrm{N}$-dioxide of pholcodine described by (Brondz and Brondz, 2012).

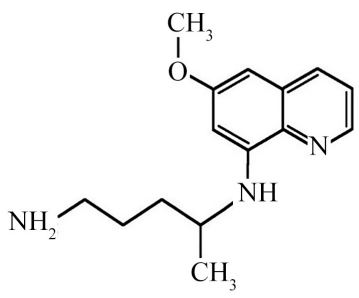

(a)<smiles>COc1cc(NCCCC(C)N)c2ncccc2c1</smiles>

(b)

Figure 8. On the left (a) is Quinocide and on the right (b) is Primaquine. 


\section{Conclusion}

An extended list of stable substances showing isomerism, enantiomerism and diastereomerism of $\mathrm{V}$-valent nitrogen was presented in this review. All these molecules are of small or medium in size. However, the possibility of stable complex heavy isomeric, enantiomeric and diastereomeric molecules with V-valent nitrogen is not excluded. This shows that stable, complex, heavy molecules with multiple centers of isomerism of $\mathrm{V}$-valent nitrogen are possible. These molecules can be as large as peptides or even proteins, where instead of carbons the nitrogen has been substituted. These molecules should not be a simple replica of the peptides or proteins with nitrogen instead of carbon. They can be quite different in architecture. Other stabilizing elements such as phosphorus, sulfur, silicon, or metals can be present. These molecules can serve as the basis of a quite different form of life in the universe. Even on the Earth, life-forms exist with an exoskeleton from chitin (such as mushrooms and insects), instead of calcium phosphate as in mammals. Insects, especially scorpions, can survive extreme radiation. Mammals have hemoglobin for oxygen/carbon dioxide exchange, which contains Fe; green plants have chlorophyll, which contains $\mathrm{Mg}$ for the same purpose; and mollusks have a hemoglobin-like substance that contains $\mathrm{Cu}$. The latter two life-forms are different from mammals. In ancient times, when humankind did not have a broad knowledge of life-forms, the red color of blood was a symbol of life. With our present knowledge, it is known that blood can be red, blue, and even colorless, as in insects. Life based on V-valent chiral nitrogen exists in the universe.

\section{Conflicts of Interest}

The author declares no conflicts of interest regarding the publication of this paper.

\section{References}

Brondz, I. (2013). Mass Spectrometric Structure Elucidation of the Trivalent and Pentavalent Nitrogen Contaminants of Pholcodine in Cough Relief Medical Form Tuxidrin. International Journal of Analytical Mass Spectrometry and Chromatography, 1, 5-10. https://doi.org/10.4236/ijamsc.2013.11002

Brondz, I., \& Brondz, A. (2012). Supercritical Fluid Chromatography-Mass Spectrometry (SFC-MS) of Heterocyclic Compounds with Trivalent and Pentavalent Nitrogen in Cough Relief Medical Forms Tuxi and Cosylan. American Journal of Analytical Chemistry, 3, 870-876. https://doi.org/10.4236/ajac.2012.312A115

Brondz, I., \& Klein, U. (2005). Separation of the Positional Isomer Quinocide from the Anti-Malarial Drug Primaquine Using a Discovery ${ }^{\circledR}$ HS F5 HPLC Column. The Reporter, 23, 1.

Brondz, I., \& Olsen, I. (1984a). Carbohydrates of Whole Defatted Cells as a Basis for Differentiation between Actinobacillus actinomycetemcomitans and Haemophilus aphrophilus. Journal of Chromatography, 311, 31-38. https://doi.org/10.1016/S0378-4347(00)84688-5

Brondz, I., \& Olsen, I. (1984b). Determination of Bound Cellular Fatty Acids in Actino- 
bacillus actinomycetemcomitans and Haemophilus aphrophilus by Gas Chromatography and Gas Chromatography-Mass Spectrometry. Journal of Chromatography, 308, 282-288. https://doi.org/10.1016/0378-4347(84)80217-0

Brondz, I., \& Olsen, I. (1985). Sugar Composition of Lipopolysaccharide from Haemophilus paraphrophilus. Journal of Chromatography, 345, 119-124. https://doi.org/10.1016/0378-4347(85)80141-9

Brondz, I., Ekeberg, D., Bell, D. S., Hustad, J. A., Svendsen, R., Vlachos, V., Oakley, P., Langley, G. J., Mohini, T., Amaury, C.-G., \& Mikhalitsyn, F. S. (2007). Nature of the Main Contaminant in the Drug Primaquine Diphosphate: SFC and SFC-MS Methods of Analysis. Journal of Pharmaceutical and Biomedical Analysis, 43, 937-944. https://doi.org/10.1016/j.jpba.2006.09.017

Brondz, I., Ekeberg, D., Karaliova, L., Jennings, I., Hustad, J. A., \& Svendsen, R. (2005c). Separation of the Positional Isomer Quinocide from the Anti-Malaria Drug Primaquine Using a Discovery ${ }^{\circledast}$ HS-F5 HPLC Column. Trends in Chromatography, 1, 78-81.

Brondz, I., Fialkov, A. B., \& Amirav, A. (2009). Analysis of Quinocide in Unprocessed Primaquine Diphosphate and Primaquine Diphosphate Tablets Using Gas Chromatography-Mass Spectrometry with Supersonic Molecular Beams. Journal of Chromatography A, 1216, 824-829. https://doi.org/10.1016/j.chroma.2008.11.043

Brondz, I., Greibrokk, T., \& Aasen, A. J. (1983a). n-1-Alkohols of Hypericum perforatum. Journal of Natural Products, 46, 940-941. https://doi.org/10.1021/np50030a025

Brondz, I., Greibrokk, T., \& Aasen, A. J. (1983b). n-Alkanes of Hypericum perforatum: A Revision. Phytochemistry, 22, 295-296. https://doi.org/10.1016/S0031-9422(00)80110-7

Brondz, I., Klein, U., Ekeberg, D., Mantzilas, D., Hvattum, E., Schultz, H., Mikhailitsyn, F. S., \& International Symposium Analytical Forum (2004b). Nature of the Main Contaminant in the Anti-Malaria Drug Primaquine Diphosphate: GC-MS Analysis. International Symposium Analytical Forum, Warsaw, 4-8 July 2004, 154.

Brondz, I., Klein, U., Ekeberg, D., Mantzilas, D., Hvattum, E., Schultz, H., \& Mikhailitsyn, F. S. (2005a). Nature of the Main Contaminant in the Anti-Malaria Drug Primaquine Diphosphate: GC-MS Analysis. Asian Journal of Chemistry, 17, 1678-1688.

Brondz, I., Klein, U., Karaliova, L., Vlachos, V., Oakley, P., Leideborg, R., \& Mikhalitsyn, F. S. (2005b). Nature of the Main Contaminant in the Drug Primaquine Diphosphate. Comparison of HPLC and SFC Methods. 29th International Symposium on High Performance Liquid Phase Separations and Related Techniques, Stockholm, 26-30 June 2005, 43.

Brondz, I., Mantzeilas, D., Klein, U., Lebedeva, M. N., Mikhailitsyn, F. S., Souleimanov, G. D., \& Ekeberg, D. (2003). The Main Contaminant of the Anti-Malaria Drug Primaquine Is Its Positional Isomer. 3rd International Symposium on Separation in BioSciences SBS 2003 a 100 Years of Chromatography, Moscow, 13-18 May 2003, 165.

Brondz, I., Mantzilas, D., Klein, U., Ekeberg, D., Hvattum, E. M., Lebedeva, M. N., Mikhailitsyn, F. S., Souleimanov, G. D., \& Røe, J. (2004a). Nature of the Main Contaminant in the Anti-Malaria Drug Primaquine Diphosphate: A Qualitative Isomer Analysis. Chromatography B: Biomedical Sciences and Applications, 800, 211-223. https://doi.org/10.1016/j.jchromb.2003.09.042

Brondz, I., Olsen, I., \& Greibrokk, T. (1983). Direct Analysis of Free Fatty Acids in Bacteria by Gas Chromatography. Journal of Chromatography, 274, 299-304. https://doi.org/10.1016/S0378-4347(00)84433-3

IUPAC (2006). Compendium of Chemical Terminology: The Gold Book (2nd ed.). Oxford: Blackwell Scientific Publications (1997). http://goldbook.iupac.org

Moss, G. P. (1996). Basic Terminology of Stereochemistry (IUPAC Recommendations 1996). Pure and Applied Chemistry, 68, 2193-2222. 
https://doi.org/10.1351/pac199668122193

https://old.iupac.org/publications/pac/1996/pdf/6812x2193.pdf

Phillipson, J. D., Handa, S. S., \& El-Dabbas, S. W. (1976). N-Oxides of Morphine, Codeine and the Baine and Their Occurrence in Papaver Species. Phytochemistry, 15, 1297-1301. https://doi.org/10.1016/0031-9422(76)90003-0 